\title{
Cosmopolitismo(s) em Tempos Midiáticos: um Desafio Contemporâneo
}

\section{Renato Cordeiro Gomes}

Professor associado da PUC-Rio, pesquisador $1 \mathrm{~A}$ do CNPq. Autor de Todas as cidades, a cidade (Rocco, 1994); João do Rio: vielas do vício, ruas da graça (Relume-Dumará, 1996); João do Rio por Renato Cordeiro Gomes (AGIR, 2005); organizou com Izabel Margato as coletâneas (ED. UFMG): O papel do intelectual hoje (2004); Literatura, Política, Cultura (2004); Espécies de espaço (2008); Literatura e Revolução (2011); Novos realismos (2012).
O cosmopolitismo é uma aventura e um ideal (Appiah) O mundo do qual falo é absolutamente heterogêneo (Derrida)

Resumo: Uma concepção de cosmopolitismo, de base eurocêntrica, é questionada por pensadores como K. A, Appiah, Walter Mignolo, Silviano Santiago entre outros, para buscar possíveis ressemantizações do termo no contexto contemporâneo, marcado pela globalização, pelo multiculturalismo e pela expansão das novas tecnologias de comunicação. Considerando esse confronto de noções de cosmopolitismo, indaga-se como se deu a interpretação do Brasil, no início do século XX, quando recrudesceram as tensões entre cosmopolitismo e nacionalismo. Busca-se, por outro lado, confrontar tais interpretações com as que surgem no início do século XXI, quando a nação vai deixando de ser o centro de um sistema de significação, em tempo heterogêneo e de globalização, em que se pode falar em "cosmopolitismo do pobre" (cosmopolitismo do subalterno), como formulou Silviano Santiago.

Palavras-chave: cosmopolitismo; globalização; multiculturalismo; sociedade em rede; cosmopolitismo do pobre

\section{Title: Cosmopolitanism(s) at Time of Media: A contemporary Challenge}

Abstract: An Eurocentric conception of cosmopolitanism is questioned by thinkers as K. , Appiah, Walter Mignolo, Silviano Santiago among others, to search possible ressemantizations of the term in the contemporary context, marked by the globalization, the multiculturalism and the expansion of the new technologies of communication. Considering this confrontation of comopolitanisms, this paper inquires how are several interpretations of Brazil, at the beginning of century XX, when the tensions between cosmopolitanism and nationalism had grown up. This research, on the other hand, aims to confront such interpretations with those that appear at the beginning of century XXI, when the nation is anymore the center of a system of signification, at heterogeneous time and of globalization, when is it possible to speak in "cosmopolitismo do pobre" (subaltern cosmopolitanism) formulated by Silviano Santiago.

Keywords: cosmopolitanism; globalization; multiculturalism; network society; subaltern cosmopolitanism; 


\section{Cosmopolitismo: um tópico da agenda multicultural}

No contexto contemporâneo, o conceito de cosmopolitismo foi substituído por globalização, ou mesmo multiculturalismo (ambas as palavras de circulação mais recente, de meados do século XX, nas acepções que nos interessam)? - talvez não fosse ocioso indagar. A questão agudiza-se se considerarmos alguns fenômenos, além da dramática atualidade internacional, como o avanço das tecnologias de comunicação, a progressiva pluralização do território gerada pelas mídias com o advento das redes digitais, e da hibridação entre informação e território, ou ainda a crise do "Estado-nação moderno como uma organização compacta e isomórfica de território, etnia e aparato governamental" (APPADURAI, 1997: 34), as formas de circulação de pessoas características do mundo contemporâneo, do turismo à imigração, às diásporas por causas diversas, que podem ser relacionadas ao que Appadurai denomina "cartografias pós-nacionais". Para este pensador, "o movimento humano costuma ser decisivo na vida social" (1997: 35), como prova o fluxo de imigrantes em busca de trabalho e melhores condições de vida nos países ricos e hegemônicos, antigos senhores de impérios coloniais.

Observando tais fenômenos, o filósofo inglês-ganense Kwame Anthony Appiah, no livro Cosmopolitanism - Ethics in a world of strangers (2006; ed. em espanhol, 2007) procura nomear o processo pelo qual podemos não só influir nas vidas de todo o planeta, mas também aprender sobre a vida que se desenvolve em qualquer lugar, o que é possibilitado pela rede de informação mundial: o rádio, a televisão, os telefones, a Internet, as redes sociais..., possibilitado pela expansão de novas tecnologias e pelo acesso a esses aparatos por um número cada vez maior de cidadãos (fala-se em inclusão digital). Ao descartar os termos "globalização", por hoje abarcar tudo e nada por sua vez, e "multiculturalismo", "termo deformador, que frequentemente designa a enfermidade que pretende curar" (APPIAH, 2007: 16), opta pelo termo "cosmopolitismo", mesmo frente ao seu polêmico significado, que pode sugerir uma desagradável atitude de superioridade ante o supostamente provinciano (preconceito que todos nós cometemos com certa frequência).

As acepções de cosmopolitismo e seus correlatos, nos dicionários, permitem estabelecer alguns traços semânticos, que, de uma forma ou de outra, se articulam nas configurações do(s) cosmopolitismo(s) e sua aclimatação aos espaços e às temporalidades várias e simultâneas na contemporaneidade. Assim, podemos considerar aqueles traços pertinentes às acepções dicionarizadas (Houaiss, Aurélio, Petit Larrousse, Oxford Dicionary): racionalidade, ordem, urbanidade, estrangeiridade, dissolução das fronteiras nacionais, cidadania; o que vem dos grandes centros urbanos, apresentando características análogas; deslocamento, contato entre povos e culturas, experiência do mundo, universalidade ... Traços que, por sua vez, podem passar a conceitos que têm sua história, a começar talvez no cinismo e no estoicismo da antiga Grécia, com Diógenes, para quem a verdadeira natureza humana, cujo pertencimento à humanidade - a cidadania universal (Kosmopolites $=$ cidadão universal) - supera qualquer vinculação a um Estado específico, concepção que foi adotada e elaborada pelos estoicos, o que - sublinha Appiah (2007: 16) - adquiriu importância central durante a história intelectual ulterior do termo. Reelaborado pelos romanos Cícero, Sêneca, Epicteto e Marco Aurélio, foi apropriado por muitos intelectuais cristãos, ecoando nas palavras de São Paulo: "já não há judeu nem grego; nem escravo nem livre; nem homem nem mulher, já que todos vós sois um em Cristo Jesus" (APPIAH, 2007: 17).

A história do termo tem um momento decisivo com o lluminismo, base para o cosmopolitismo moderno, para o qual há uma ética cosmopolita em que todos os seres humanos são tratados como se fossem cidadãos do cosmos (no sentido de universo). Nesta ótica, por exemplo, marcam-se traços morais da "Declaração dos Direitos do Homem", de 1789, bem como em Voltaire que fala da "República cosmopolita da humanidade", e Diderot que vê o homem enquanto membro da 
grande cidade do mundo, ou a obra de Kant que propunha a "liga das nações" e prega a dissolução das fronteiras nacionais que caracteriza a culminância de uma racionalidade do desenvolvimento histórico da humanidade, decorrência de uma racionalidade plena e pacificação nas relações humanas - a paz perpétua, que ecoa na visada crítica de Appiah (ver também a conferência "Mi cosmopolitismo - 2008) que "emerge da agenda multicultural" e "se insurge contra a tomada de poder universal pelos fundamentalistas", "os que negam a legitimidade da universalidade e os que negam a legitimidade da diferença, os que compartem a crença pela universalidade, sem simpatia pela diferença", e propõe um cosmopolitismo que passe pelo pluralismo, abrigando "a esperança e expectativa de que diversas pessoas e sociedades modelem valores diferentes", como registra Silviano Santiago, em "Ėtica e diversidade cultural", cujo título original, segundo o autor, era "Cosmopolitismo e diversidade cultural" (2011:2).

Para o filósofo ganense-britânico, na noção de cosmopolitismo se entrelaçam dois aspectos:

Um deles é a ideia de que temos obrigações que se estendem para mais além daqueles a quem nos vinculam laços de parentesco, inclusive os laços mais formais da cidadania compartilhada. O outro consiste em levar em conta seriamente o valor, não só da vida humana, mas também das vidas humanas particulares, o que implica interessar-nos pelas práticas e crenças que thes outorgam significado. (APPIAH, 2007: 18)

Para Appiah, ao contrário da homogeneização dos valores e ações, é extremamente relevante para o cosmopolita considerar as diferenças. Entretanto haverá momentos em que aqueles dois ideais - o interesse pelo universal e o respeito pelas legítimas diferenças, entraram em conflito. Neste sentido vale a pena recolher a síntese do pensamento de Appiah que Silviano Santiago elabora no artigo "Ética e diversidade cultural" (2011:2):

Impregnado pelo multiculturalismo doméstico, o futuro professor de filosofia direciona estudos e pesquisa por um dos ideais do estoicismo-o cosmopolitismo. Dele extrai sua concepção multiculturalista, recheando-a com os ideais do Iluminismo europeu, com o projeto de paz perpétua, defendido por Kant, e com o nacionalismo romântico explorado por Herder. Na efervescência da globalização econômica, que excita a diáspora dos povos periféricos, o cosmopolitismo se faz necessário por ter abraçado o amplo leque da legítima diversidade humana. Seu ideário se apresenta em três vertentes. 1. Não necessitamos de um governo mundial único. 2. Devemos preocupar-nos pela sorte de todos os seres humanos, tanto os da nossa sociedade como os das outras. 3 . Temos muito a ganhar nas conversações que atravessam as diferenças.

Essas questões são retomadas em entrevista do filósofo, professor da Universidade de Princeton, na entrevista a Guilherme Freitas, publicada no Prosa \& Verso, de $O$ Globo (5/1/2013), quando do lançamento no Brasil de $O$ código de honra (Companhia das Letras). Defendendo o diálogo entre culturas como tema central da sua obra, responde à pergunta “Como define o 'cosmopolitismo' e qual o lugar das artes nele?", declara:

Um diálogo intercultural cosmopolita é aquele em que nos tratamos como cidadãos de um mundo compartilhado, e portanto dignos de respeito mútuo. Isso não significa que não podemos discordar. Por um lado, não podemos ser apenas relativistas generalizadores e achar que tudo que acontece na Humanidade é correto e bom. Por outro, não podemos achar que nós temos todas as respostas, seja lá quem seja esse "nós". Temos de nos colocar em um diálogo no qual imaginemos que podemos aprender com o outro. Por meio do 
engajamento com as artes de outra comunidade, posso manifestar respeito por ela, aprender sobre ela. A arte é também um mecanismo de troca entre sociedades. Além disso, levar a sério as artes de outra cultura fortalece uma idéia de comunidade global na qual todos são importantes. E isso não significa assumir que tudo que vem de fora é bom, porque levar a sério outra cultura é submetê-la ao mesmo padrão crítico que se usa para a sua. O contrário é condescendente, desrespeitoso, não é cosmopolita (2013:3).

Essa precisa síntese critica um cosmopolitismo eurocêntrico, hegemônico, que se queria universal, abalado que fora pelo pensamento pós-colonial e pelo multiculturalismo. Sublinha os traços relevantes do cosmopolitismo atual que exorta o cidadão à reflexão ética, ao fazer frente ao relativismo generalizador e aos fundamentalismos, cujo universalismo se expressa na uniformidade. No cosmopolitismo atual, "pluralidade efalibilidade encaminham e balizama 'conversação cosmopolita' [da qual a arte participa], que passa entre barreiras culturais, políticas, sociais, econômicas e religiosas - ressalta Santiago e acrescenta:

A conversação não visa à conversão absoluta de um ou do outro falante; seu propósito, afirma Appiah, é o aprendizado, além do ensino, é a escuta, além da fala. A conversação global é também uma metáfora. E o é, porque só podemos conversar com os milhões de habitantes do planeta através da antropologia e da história, da literatura, do cinema e das notícias veiculadas pelos jornais, rádio, televisão e Internet (SANTIAGO, 2011:2).

A conversação cosmopolita, portanto, expande-se com a expansão das mídias.

Como revela a coletânea The Cosmopolitanism Reader (2011), editada por Garrett Wallace Brown e David Held, o cosmopolitismo é uma filosofia para a idade da interconexão humana e gera políticas para o "pequeno mundo"; é uma rica e abrangente teoria política que cobre grande possibilidade de saídas morais e práticas para o mundo contemporâneo, em que se constata a percepção de que o mundo se tornou incrivelmente interconectado (em sentido positivo e negativo) - o que se atrela ao desenvolvimento das tecnologias de comunicação (BROWN \& HELD, 2011: 1-13).

Depois de Kant, o cosmopolitismo ficou dormindo como um desafio subterrâneo também para a ética de um poderoso liberalismo competitivo, com todo tipo de conotações, ou para a política do estado-nação que cresceu no nacionalismo e na luta de classes. $O$ cosmopolitismo agora cresce das sombras e abala muitas de suas conotações negativas (o cosmopolita visto como traidor das solidariedades nacionais). Desafios são colocados para os poderes soberanos do estado (por exemplo, a formação da União Europeia e o neoliberalismo) e para a coerência da ideia de nação e de estado (os fluxos massivos de capital sem fronteiras, movimentos migratórios, trocas culturais) abriram espaço para uma retomada do conceito de cosmopolitismo como um caminho de aproximação do políticoeconômico global, cultural e questões legais.

Por este quadro geral, podemos destacar o que conclui Appiah: "Em um sentido, longe de ser o nome da solução, o cosmopolitismo é o nome do desafio" (2007: 19).

\section{Universalismo X nacionalismo: um Brasil cosmopolita?}

Esse desafio em relação ao cosmopolitismo é um problema candente para a construção do Brasil como nação, enquanto "comunidade imaginada" (Benedict Anderson) e condiciona muitos intérpretes do país em seu processo de diferenciação cultural que se atrela a formas de representação que ganham a função político-ideológica, enquanto traço articulador do projeto histórico de constituição (de formação) de nossa identidade cultural, processo que abala os conceitos de pureza e unidade. 
Essas ideias aqui elencadas nos servem de pano de fundo para apontar como as tensões dialéticas entre cosmopolitismo e provincianismo, ou dito de outras formas, entre o global e o local, entre o geral e o particular, entre centro e periferia, entre autonomia e dependência, universalismo (eurocentrismo) e nacionalismo ... bem como a expansão das mídias, condicionaram as interpretações do Brasil no início dos séculos XX e XXI, em que a expansão das novas tecnologias de cada época imprime novos ritos e ritmos à vida cotidiana das cidades.

Outras nuances da questão extrapolam o campo da arte para ampliar-se pela cultura, pela política, pela economia, pela antropologia, agudizando as tensões entre cosmopolitismo e nacionalismo [como na formulação de Antonio Candido: "Se fosse possível estabelecer uma lei da evolução de nossa vida espiritual, poderíamos dizer que toda ela se rege pela dialética do localismo e do cosmopolitismo manifestada pelos modos mais diversos" (1965: 129)], sobretudo em tempos de globalização da economia e da própria cultura, que provocam a circulação de discursos que buscam minimizar a centralidade da Nação para a significação do mundo, ora revestem-se de estratégias de resistência à perda dos referenciais locais (a cultura condicionada pela geopolítica). Em ambas as modalidades de discurso adotam uma enunciação que se pauta por retóricas diversas de convencimento.

Em certos momentos históricos, a retórica queria convencer que a superação do atraso indicava a possibilidade da realização de uma Europa possível nos trópicos, identificada ao cosmopolitismo, que é uma ideia eurocêntrica. Tal estratégia implicava "imitar a Europa", não importando muito as diferenças e as temporalidades diversas. Neste sentido, insere-se a Exposição Nacional de 1908, em que se comemoravam 100 anos da abertura dos portos às nações amigas, que prenuncia a Exposição Internacional de 1922, em comemoração dos 100 anos da independência do Brasil, ambas no Rio de Janeiro, ambas como projetos oficiais da República, em suas preocupações de feição cosmopolita, ligadas à inserção compulsória do Brasil no concerto das nações civilizadas.

Deste modo bem pouco dialético, o projeto da República põe em prática um plano de progresso e modernização cosmopolita, que, entre outras medidas, empreendeu as reformas de Pereira Passos, inaugurando novos ritos e ritmos em sua cidade-capital, na primeira década do século XX., sob o lema do "Rio civilizase", cujos emblemas foram a Avenida Central e o novo porto modernizado, que se abria para fora e por onde entravam as novidades do moderno. "A civilização do Brasil divide-se em duas épocas: antes e depois da Avenida Central. Entre a rua do Ouvidor e a Avenida vai uma distância como de Sabará a Marselha" - afirma João do Rio, em crônica do jornal O Paiz (1920: 115-116), certamente o escritor da Belle Époque mais afinado com o cosmopolitismo que copia os padrões europeus, sobretudo os mais identificados com a vida parisiense, com o mundanismo, a frivolidade, os modismos, e os aparatos modernos (o cinematógrafo, a imprensa a cores e ilustrada, o fonógrafo, a fotografia, o automóvel - "o grande sugestionador" dessa vida vertiginosa), buscando estabelecer a ligação entre modernização e cosmopolitismo, em sua tradução nos trópicos, superposição que interessava às elites aburguesadas. João do Rio, ao mesmo tempo em que exalta essa modernização cosmopolita, deixa em suspensão um nacionalismo difuso, que aflora, de vez em quando, como, por exemplo, para lamentar a destruição do Rio pitoresco e único, ou perguntar quando o brasileiro vai conhecer o seu país. É um intérprete do Brasil por essa clave cosmopolita, em que "o lá (sempre Paris) aparece substituindo as experiências primárias do cá [...] cuja consequência lógica é a desterritorialização, processo transitivo da cultura moderna" (ANTELO, 1989: 16).

O Rio de Janeiro - Cidade-Espelho, assim denominado em crônica de $O$ Paiz, de $6 / 3 / 1920$, que se moderniza encarna, então, esse cosmopolitismo de imitação. Tal qual a moda, as cidades também elegem os seus modelos e tentam apagar as 
diferenças. "De súbito, da noite para o dia, compreendeu-se que era preciso ser tal qual Buenos Aires, que é esforço despedaçante de ser Paris", constata Joe, um dos pseudônimos de Paulo Barreto, em crônica da coluna "Cinematographo", da Gazeta de Notícias. Nesse texto em que lamenta a demolição do velho mercado, em nome da mudança, traço forte da modernidade que se identifica com o progresso, e este com o futuro, ressalta serem o característico, o local, o típico, o exótico de cada urbe, a legitimação da identidade (faz parte de um sistema de significação), que o cosmopolitismo veio destruir. O progresso e seus correlatos nivelam cidades, almas, gostos, costumes, moda. É justamente pela analogia com a moda que critica, nesta crônica ("Velho mercado") o apagamento do velho Rio:

(...) a civilização é a igualdade num certo poste, que de comum acordo se julga admirável, e, assim como as damas ocidentais usam os mesmos chapéus, os mesmos tecidos, o mesmo andar, assim como dous homens bem vestidos hão de fatalmente ter o mesmo feitio da gola do casaco e do chapéu, todas as cidades modernas têm avenidas largas, squares, mercados e palácios de ferro, vidro e cerâmica (RIO, 1909: 214).

O padrão cosmopolita apresentado é atrelado ao desenvolvimento do capitalismo, à expansão dos mercados, ao universo do consumo que se globalizava. Um pouco antes dissera: "Uma cidade moderna é como todas as cidades modernas", para registrar que dos escombros do velho Rio "surgiu a urbs conforme a civilização, como ao carioca bem carioca, surgia da cabeça aos pés o reflexo cinematográfico do homem de outras cidades. Foi como nas mágicas, quando há mutação para a apoteose" (RIO, 1009: 213).

Com toda certeza, posicionamento mais contundente é assegurado por Joaquim Nabuco, pelo viés da autobiografia em Minha formação (1900) (a autobiografia é também o dispositivo discursivo que Appiah lança mão para falar de "seu cosmopolitismo" - Mi cosmopolitismo), com destaque para o capítulo "Atração do mundo". Se o sentido de formação está presente em textos (Sérgio Buarque, Caio Prado Júnior, Antonio Candido, Celso Furtado etc.) que procuravam interpretar o Brasil no momento em que estava em pauta a construção do Brasil moderno, a acepção de Nabuco, na abertura do século XX, indica "o amadurecimento pessoal e cultural do cidadão brasileiro, por uma modelagem subjetiva". Numa linha derivada de Kant, Nabuco "reflete sobre o modo como o brasileiro, caso perca a menoridade política, pode transformar-se em sujeito da história nacional, embora ainda fique sujeito à formação ministrada pela Europa moderna e à dependência da cultura ocidental", como sublinha Santiago, em "Raízes do Brasil cosmopolita" (2011: 2). Nabuco, em sua escrita rememorativa, levada entre os dois lados do Atlântico, observa: "De um lado do mar, sente-se a ausência do mundo; do outro, a ausência do país". Continua Santiago: "Na autobiografia, Nabuco se rende ao movimento e processo de universalização da história ocidental e, cidadão letrado, se entristece com a função que o Brasil teve como colônia e se entusiasma pelo papel que o país livre pode ocupar" (2011: 2). Confessa Nabuco: "Sou antes um espectador do meu século do que do meu país; a peça é para mim a civilização, e se está representando em todos os teatros da humanidade, ligados pelo telégrafo". E acrescenta Santiago: "Se se atualizar a telegrafia pela televisão e a internet, teremos o brasileiro letrado de hoje" (2011:2).

As tensões, portanto, entre o nacional e o cosmopolita pautavam não só as relações internacionais, econômicas, políticas, sociais e culturais do Brasil, nessa época de implantação da República e da "vontade de moderno" (a expressão é de Paulo Herkenhoff). Estava em questão a contradição de uma vida e uma cultura cosmopolitas expressarem a identidade nacional, tema fulcral desse tempo (cf. João do Rio, Lima Barreto e Euclides da Cunha). Tal problemática serve como ponte ideológica para o Modernismo, que busca aliar a linguagem de vanguarda e "descobrir o Brasil", na tentativa de combater a moléstia de Nabuco de que 
fala Mário de Andrade em correspondência a Drummond, e pode surpreender sua permanência pelo século $X X$, dando continuidade (em diferença) ao projeto romântico cujo patrono é José de Alencar.

Essas questões podem reatualizar a discussão sobre o compromisso com o espaço cultural e geográfico de origem - o local, hoje posto em xeque com o processo de desapropriação pelo global. Como tais questões deste início de século XXI permitem rever as tensões entre o nacional e o cosmopolita, entre a cultura local e a cultura mundial? Cabe então perguntar se, na reflexão sobre o lugar e a forma de produção do conhecimento contemporâneo, há um sentido único quando se refere a "cosmopolitismo". Certamente, não é à toa que a introdução assinada por Carol A. Breckenridge, Sheldon Pollock, Hommi K. Bhabha e Dipesh Chakrabarty da coletânea Cosmopolitanism por eles editada, intitule-se exatamente "Cosmopolitanisms" (no plural) e afirmarem que "especificar positivamente e definitivamente cosmopolitismo é uma coisa não cosmopolita" (2002: 1). É para eles uma categoria histórica que deveria ser considerada inteiramente aberta e não um conceito determinado a priori pela definição de uma sociedade ou de um discurso particular. Impõe-se, então, - é a lição da referida coletânea com ensaios de intelectuais de várias procedências - repensar o conceito dos diversos cosmopolitismos, num solo histórico, a partir dos dias atuais, em que se declara o fim da centralidade do Estado-nação como sistema de significação. Neste momento pós-moderno e pós-colonial, o cosmopolitismo não pode mais ser articulado a partir de um único ponto de vista, uma mono-lógica. É necessário levar em consideração a diversidade e o discurso dos que estão à margem.

"A globalização diminui a importância dos acontecimentos fundadores e dos territórios que sustentavam a ilusão de identidades a-históricas e ensimesmadas" - afirma Canclini (1995: 124). Dão-se os embates advindos da coexistência tensa entre o local e o global, em que novas características temporais e espaciais resultam na compressão de distâncias e de escalas temporais, o que pode se abrir para uma nova modalidade de cosmopolitismo, sem referência ao Estado-nação, mas ligado à economia globalizada, à desnacionalização, como foi a proposta da Bienal de São Paulo de 2004, que rompeu fronteiras geopolíticas, extinguindo as representações nacionais. Vale dizer que esse fato indica que as formas e as forças de identidade são menos sociais e mais culturais, num tempo em que novos modos de simbolização e ritualização dos laços sociais se tecem pela mediação das redes comunicacionais e dos fluxos informacionais (MARTíN-BARBERO, 2004: 258).

\section{O cosmopolitismo do pobre}

O cosmopolitismo é um tema recorrente em Silviano Santiago, tanto na sua obra de ficção como em sua produção de crítica literária e crítica cultural. Um cosmopolitismo que se situa a partir da margem, de uma província ultramarina, e que busca enfrentar questões que vão desde o nacionalismo, a identidade moderna da cultura brasileira, o papel do intelectual moderno e pós-moderno, a viagem ao estrangeiro, as tensões entre as culturas locais e as globalizadas, a relevância dos meios de comunicação, sem esquecer o conceito de "entre-lugar" trabalhado desde o ensaio de 1974, ao romance Viagem ao México (1995), um conceito que se repete em-diferença, passando pelo ensaio "Apesar de dependente, universal" (de Vale quanto pesa, 1982) e o ensaio As raízes e o labirinto da América Latina (2006). Nesse périplo, diz Santiago:

a leitura de Minha formação, de Joaquim Nabuco, me ajudou a dar o último passo, assim como a experiência de ter visto o filme de Manoel de Oliveira, Viagem ao começo do mundo (1997). E, finalmente, está sendo também importantíssima a leitura de El laberinto de la soledad, de Octavio Paz, de onde extraí a figura do pachuco, que se tornou o novo avatar do entre-lugar. (...) Somados todos, comecei a trabalhar a questão da diáspora, de uma perspectiva 
lusa, luso-brasileira, hispano-americana, latino-americana. Cada adjetivo carreia consigo os problemas específicos, tanto geográficos quanto sociais e econômicos, decorrentes da situação em análise. Acabo de escrever um ensaio, As raízes e o labirinto da América Latina, que dará ao leitor - para o bem e para o mal - o último formato da questão (SANTIAGO, 2006: 365).

Por esse viés, perpassa a questão do cosmopolitismo, contextualizada num tempo (o contemporâneo) em que se experimenta o processo de aceleração da história marcado pela superabundância de fatos e informações e pela emergência de interdependências em escala inédita no sistema-mundo e pelo desenvolvimento tecnológico, como formularam Canclini e Matín-Barbero citados há pouco, a que se juntam os fenômenos da desterritorialização e os efeitos da homogeneização, num tempo heterogêneo (ver CHATERJEE, 2009).

Essas contradições põem em xeque o compromisso com o espaço cultural e geográfico de origem - o local, com o processo de desapropriação pelo global. Cabe então perguntar se, na reflexão sobre o lugar e a forma de produção do conhecimento contemporâneo, há um sentido único quando se refere a "cosmopolitismo". Esse é um tipo de provocação que os textos de Silviano incitam, e vêm juntar-se a ideias estampadas em textos de Appiah ou na já citada coletânea Cosmopolitanism. Em tal contexto a circulação prevalece sobre a produção, que também define o padrão geográfico, já que é mais densa, mais extensa, e detém o comando das mudanças de valor do espaço - observa Martín-Barbero (2004: 260). E acrescenta, para destacar que a nova significação do mundo não é derivável do Estado-nação:

as redes põem em circulação fluxos de informação e movimentos de integração à globalidade econômica, a produção de um novo tipo de espaço reticulado que debilita as fronteiras do nacional e do local ao mesmo tempo em que converte esses territórios em pontos de acesso e transmissão, de ativação e transformação de comunicar e de poder" (MARTíN-BARBERO, 2004: 260).

O ensaio de Santiago que acabou dando título a uma coletânea publicada pela Ed. UFMG, pode perfeitamente inscrever-se na figura de deslocamento para a margem que caracteriza o cosmopolitismo do pobre (o cosmopolitismo do subalterno), como é "pobre" todo o cosmopolitismo que se define a partir da margem, fora dos centros hegemônicos, diz o autor em entrevista (a ela voltaremos). Esse deslocamento da voz está atrelado ao momento atual que se abre para um mundo transnacional (mesmo com as contradições provocadas pelos fundamentalismos, pelo pós 11 de setembro, pela crise na zona do euro entre outros acontecimentos).

É nesse sentido que Santiago, depois de demonstrar, no ensaio "Atração do mundo", a partir das ideias de Joaquim Nabuco, o percurso político-cultural de nossa modernidade tardia, na base das tensões entre as exigências localistas e o cosmopolitismo identificado com a cultura européia, irá propor um "cosmopolitismo do pobre", a que poderíamos opor um "cosmopolitismo do rico" [o termo é meu, não de Santiago] (ligado ao "multiculturalismo antigo", no âmbito do qual surgiu o termo etnocentrismo, cunhado pelo norte-americano William G. Summer, em 1906 - informa Silviano), aquele analisado a partir de Minha formação (1900), de Nabuco, cosmopolitismo que Mário de Andrade em carta de 1924, ao jovem Drummond, chamou de "moléstia de Nabuco" (suspirar pelo Sena, na Quinta da Boa Vista).

Elegendo como ponto de partida o filme Viagem ao começo do mundo (1997), do português Manuel de Oliveira, Silviano mostra como está surgindo uma nova forma de "desigualdade social que não pode ser compreendida no âmbito legal de um Estado-nação, nem pelas relações oficiais entre governos nacionais, já que a razão econômica que os convoca para a metrópole pós-moderna é transnacional 
e é também clandestina" (2002: 7). Se há uma nova forma de multiculturalismo que só pode ser compreendido num processo de "desnacionalização do espaço urbano" e "desnacionalização da política" (SASSEN, 1991), e se há os trânsitos de desprivilegiados do mundo, uma nova forma de cosmopolitismo emerge desse influxo de imigrantes pobres nas metrópoles pós-modernas, da mesma maneira que resgata grupos étnicos e sociais economicamente desfavorecidos no processo de multiculturalismo a serviço do Estado-nação. Esse novo cosmopolitismo do subalterno conta com o apoio de movimentos políticos transnacionais, em especial pelas ONGs, que defendem os direitos das minorias e com dispositivos de comunicação e das mídias possibilitados pelas novas tecnologias, cujas redes ensejam as conexões com o sistema mundo. Novas formas de cosmopolitismo permitem, portanto, expressar novos projetos políticos, éticos e culturais, a partir de perspectivas marginais, ou seja, do deslocamento de centros hegemônicos que marcaram a tradição cosmopolita.

Em entrevista publicada no n. 7 da revista Metamorfose (2006), a uma pergunta formulada por mim, Santiago responde, ampliando e nuançando a questão. Vale a pena a citação longa:

Do urbano ao cosmopolita. Você é um dos editores da revista bilíngüe Margens/ Márgenes e publicou no n.2 um ensaio "O cosmopolitismo do pobre" (que forneceu o título da coletânea de ensaios, publicada pela Ed. UFMG . Há por oposição um cosmopolitismo do rico, como o que você fala em seu ensaio "Atração do mundo", centrado na figura de Joaquim Nabuco do livro de memórias Minha formação?

Infelizmente, somos todos, aqueles que o são, - y inclus Joaquim Nabuco -, cosmopolitas pobres. Esse é um dos lances teóricos do meu livro de ensaios. Repare que a situação familiar ou financeira, abastada, deste ou daquele brasileiro, ou latino-americano, a classe social superior a que pertence, não o diferencia do cosmopolita propriamente pobre, sem recursos financeiros, que toma o avião da Varig e vai comer o pão que o diabo amassou nos Estados Unidos. Veja que, se um dos meus artigos começa por Nabuco, o outro começa pelo notável filme de Manoel de Oliveira, um português que se situava na União Européia. A condição de pobre é a de estar na margem e à margem da História, como fica claro em Minha formação, de Joaquim Nabuco. No wired world em que vivemos, a diferença entre o brasileiro rico e o brasileiro pobre reside no fato de que o primeiro não precisa viajar e o segundo viaja, mas mesmo assim, em nossos dias, não precisa tanto viajar para ser cosmopolita. Como escreve Nabuco, no Brasil sente saudades da Europa, na Europa sente saudades do Brasil. É essa situação entre que nos torna a nós, brasileiros, cosmopolitas pobres. O brasileiro pode até ser um nacionalista rico, e os há, e relativamente poucos, mas, se passar à condição de cosmopolita, será sempre um cosmopolita pobre. [.....]

o que estou querendo dizer é que há novas, precárias e fragmentadas utopias no mundo pós-moderno. Muitos grupos de cidadãos estão "aquém e além do nacional", no que me aproximo de filósofos como Habermas. Há um componente nacional que precisa ser (re)trabalhado em conformidade com a situação geográfica e tecnológica atual, onde a Internet (por exemplo) possibilita o congraçamento de grupos até então distantes e alheios um ao outro, mas passíveis de serem reorganizados a partir de uma concepção de identidade mais ampla. Os cidadãos estão aquém (porque pertencem a grupos minoritários nacionalmente, desprivilegiados que são pelo poder central) e estão além (porque fazem aliança com outros grupos minoritários estrangeiros, desprivilegiados que são pela globalização) do nacional. [.....]

O perigo dos ideais cosmopolitas surge no momento em que a perspectiva de avaliação do estado-nação transforma-se em julgamento de valor, ou seja, quando tudo o que não era europeu no Brasil, tudo o que não é norte-americano no Brasil, era/é menor, era/é adjetivo e não substantivo. No extremo oposto, surge outro grande perigo: julgar que tudo o que é autenticamente brasileiro era/é superior, era/é substantivo e não adjetivo. (SANTIAGO, 2006, p.362-364) 
Essas achegas aos dois ensaios "Atração do mundo" e "O cosmopolitismo do pobre" levam, entretanto, a certas indagações, que arrolo, aqui, em itens (apenas como sinalizações, pois não há espaço para desenvolvê-los):

1) se todo e qualquer cosmopolitismo da margem é "pobre", não se corre o risco de perder as marcas de classe e de poder econômico, que não foram abolidas pela globalização, pela diáspora?

2) Nesse sentido, parece-me que a margem que Nabuco ocupava não seria a mesma do imigrante pobre de hoje: o pachuco, que o próprio Silviano cuidadosamente lê a partir de Octavio Paz, no ensaio As raízes e o labirinto da América Latina, de 2006; os brasileiros pobres que trabalham, hoje, nos Estados Unidos [cf a telenovela América, de Gloria Perez]. Temos que considerar que os contextos históricos são outros. Se for verdade que são iguais (somos todos cosmopolitas pobres, embora haja pobres e pobres, nem tão iguais assim, a não ser que "pobreza" seja um dado essencializado ligado à origem, localizada à margem dos centros hegemônicos, nos tristes trópicos), estaria Mário de Andrade equivocado quando classificou a "moléstia de Nabuco", que Silviano aborda em "Atração do mundo" e nos comentários da correspondência Mário\&Carlos?

3) A oposição mais contundente do texto seria cosmopolitismo do pobre $X$ nacionalista rico (seria interessante um exercício em que se buscaria equacionar as implicações políticas, sociais e culturais dessa equação).

4) $\mathrm{Na}$ entrevista que estamos citando, não estaria Silviano recolocando o cosmopolitismo num centramento, que o ensaio "Cosmopolitismo do pobre" procura deslocar para pensá-lo a partir da margem, como também revela a proposta de Ricardo Piglia em Tres propuestas para el próximo milenio (y cinco dificultades)?

5) O cosmopolitismo do pobre como suplemento da cultura ocidental contemporânea seria outra forma de nomear as relações entre cosmopolitismo e localismo, que ganha outras nuances frente a uma cultura globalizada, necessariamente midiatizada?

Por essa ótica de base transnacional, como postula Bhabha e Mignolo, as narrativas legitimadoras da dominação cultural ainda estruturadas numa lógica binária de centro e periferia, hierquizadora e eurocêntrica, pode ser deslocada para revelar o que Bhabha chama de "terceiro espaço", em que convivem momentos diferentes do tempo histórico - um tempo heterogêneo teorizado por Chaterjee (2009). Ou dito com outras palavras, "a temporalidade não-sincrônica das culturas nacional e global abre um espaço cultural - um terceiro espaço - onde a negociação das diferenças incomensuráveis cria uma tensão peculiar às existências fronteiriças" (BHABHA, 1998: 300). Esta concepção está bem próxima do conceito de entrelugar formulado por Santiago, no ensaio de 1971 "O entre-lugar do discurso latinoamericano" (1978), quando, motivado pelas teorias da dependência, procura uma metodologia de leitura para ler o lugar de transgressão das literaturas produzidas nos trópicos. A astúcia do olhar periférico, olhar enviesado, que avalia a dependência cultural, para além do econômico, não para negá-la, mas como atitude afirmativa capaz de auto-conhecer-se como valor diferencial. Um pé lá, outro cá, num entre-lugar, lugar diferido, pensa-se uma cultura e uma literatura do ponto de vista de uma província ultramarina ou dos subúrbios da periferia (para usar a imagem de Piglia), repensando conceitos etnocêntricos, debilitando esquemas cristalizados de unidade, pureza e autenticidade. Esse descentramento desloca a cultura européia de seu lugar privilegiado de cultura de referência postura inspirada em Derrida - pondo em causa a descolonização do pensamento brasileiro e latino-americano. Transmutação dos valores, que o contato entre culturas diferentes provoca. Entre assimilação e agressividade, aprendizagem e 
reação, obediência e rebelião, realiza-se "o ritual antropofágico da cultura latinoamericana", aquele que se faz de temporalidades disjuntivas, múltiplas e tensas, temporalidade de entre-lugar, que desestabiliza o significado da cultura nacional como homogênea, pois é uma cultura dividida no interior dela própria, articulando sua heterogeneidade e seu hibridismo (BHABHA, 1998:. 209).

Tal processo faz gerar uma poética do reposicionamento e reinscrição que permite olhar as coisas a partir da margem que, como não tem a longa tradição cultural dos centros hegemônicos, pode trabalhar com a noção de anacronismo, em que a defasagem temporal se torna uma vantagem (FIGUEIREDO, 1994), porque pode embaralhar, ou transgredir, aquela tradição que não lhe é própria, ou que passa a sê-lo à medida que é realocada, antropofagizada, ressemantizando-a com dose de suplementaridade; o suplemento como sinal de adição, que possibilita, sem anular as tensões de toda ordem, ao pobre das margens, dos subúrbios do mundo, inserir-se nos cosmopolitismos de uma "ordem" que se quer globalizada. Apesar de dependente, universal? Melhor, apesar de localista, ou por isso mesmo, cosmopolita. Certamente, a atração do mundo que sempre seduziu as margens tenha ganhado em amplitude e atrela-se aos fundos do capital financeiro e cultural que circula pela Cosmópolis contemporânea, que exige o reconhecimento da singularidade da diferença, da singularidade do outro.

\section{Referências Bibliográficas}

ANDERSON, Benedict. Comunidades imaginadas: reflexões sobre a origem e a difusão do nacionalismo. São Paulo: Companhia das Letras, 2008.

ANTELO, Raul. João do Rio: o dândi e a especulação. Rio de Janeiro: Taurus-Timbre, 1989.

APPADURAI, Arjun. Soberania sem territorialidade. Notas para uma geografia pósnacional. Novos Estudos, n. 49, São Paulo: CEBRAP, nov 1997.

APPADURAI, Arjun. (ed). Globalization. Durham \& London: Duke University Press, 2001.

APPIAH, Kwame Anthony. Cosmopolitismo: A ética en un mundo de extraños. Buenos Aires: Madrid: Katz, 2007.

APPIAH, Kwame Anthony. Descolonizando os livros de História. Entrevista a Guilherme Freitas. Prosa \& Verso, O Globo, 05/01/2013, p.3.

BHABHA, Hommi. O local da cultura. Belo Horizonte: Ed, UFMG, 1998.

BRECKENRIDGE, C. A, POLLOCK, S., BHABHA, H, CHAKRABARTY, D. "Cosmopolitanisms". In: ___ (ed.). Cosmopolitanism. Durham \& London: Duke University Press, 2002.

BROWN, Garret Wallace. Kant's Cosmopolitanism. BROWN, G. W. \& HELD, D.(ed.) The Cosmopolitanism Reader. Malden, MA: Polity Press, 2010.

CANCLINI, Nestor García. A globalização imaginada. São Paulo: Iluminuras, 2003.

CANDIDO, Antonio. Literatura e sociedade. São Paulo: Nacional, 1965.

CASTELLS, Manuel. Sociedade em rede. São Paulo: Paz e Terra, 1999.

CHATERJEE, Partha. Nación en tiempo heterogeneo. Madrid: Paidós, 2009.

FIGUEIREDO, Vera Lúcia Follain de. Da profecia ao labirinto: imagens da história na ficção latino-americana contemporânea. Rio de Janeiro: Imago: UERJ, 1994 
DERRIDA, Jacques. On Cosmopolitanism. BROWN, G. W. \& HELD, D.(ed.) The Cosmopolitanism Reader. Malden, MA: Polity Press, 2010.

HELD, David. Principles of Cosmopolitan Order. BROWN, G. W. \& HELD, D.(ed.) The Cosmopolitanism Reader. Malden, MA: Polity Press, 2010.

MARTíN-BARBERO, Jesús. Ofício do cartógrafo. São Paulo: Loyola, 2004.

MIGNOLO, Walter. The many faces of cosmo-polis: border thinking and critical cosmopolitanism.

BRECKENRIDGE, C. A. et al. (ed.). Cosmopolitanism. Durham \& London: Duke University Press, 2002.

MILLER, David. Cosmopolitanism. BROWN, G. W. \& HELD, D.(ed.) The Cosmopolitanism Reader. Malden, MA: Polity Press, 2010.

NABUCO, Joaquim. Minha formação. Brasília: UNB, 1963.

PIGLIA, Ricardo. Tres propuestas para el próximo milenio (y cinco dificultades). Buenos Aires: Fundo de Cultura Económico. 2001.

RIO, João do. Cinematographo. Porto: Lello \& Irmão, 1009.

SANTIAGO. Silviano,. O entre-lugar do discurso latino-americano. Uma literatura nos trópicos: ensaios de dependência cultural. 2a ed. Rio de Janeiro: Rocco, 2000.

SANTIAGO, Silviano. As raízes e o labirinto da América Latina. Rio de Janeiro: Rocco, 2006.

SANTIAGO, Silviano. Atração do mundo: políticas de globalização e identidade na moderna cultura brasileira. $O$ cosmopolitismo do pobre: crítica literária e crítica cultural. Belo Horizonte: Ed. UFMG, 2004.

SANTIAGO, Silviano. O cosmopolitismo do pobre. O cosmopolitismo do pobre: crítica literária e crítica cultural. Belo Horizonte: Ed. UFMG, 2004.

SANTIAGO, S. Entrevista. Metamorfoses. Lisboa: Caminho; Rio de Janeiro: UFRJ, n.7, p. 349-366, 2006.

SANTIAGO, Silviano. Raízes do Brasil cosmopolita. Sabático. O Estado de São Paulo, 20/08/2011, p.2

SANTIAGO, Silviano. Ética e diversidade cultural [Cosmopolitismo e diversidade cultural]. Sabático. O Estado de São Paulo, 03/09/2011, p.2.

SANTIAGO, Silviano. Aos sábados, pela manhã. Sobre autores \& livros. Org. Frederico Coelho. Rio de Janeiro: Rocco, 2013.

SASSEN, Saskia The Global City. New York: London: Princeton: Princeton University Press, 1991. 